\title{
Kinetics of allantoin metabolism in sheep
}

\author{
L. P. Kahn* and J. V. Nolan \\ School of Rural Science and Natural Resources, University of New England, Armidale, NSW 2351, Australia
}

(Received 5 January 2000 - Revised 10 April 2000 - Accepted 3 May 2000)

\begin{abstract}
The kinetics of allantoin metabolism were studied in rumen-cannulated sheep by means of a single intravenous injection of $\left[4,5-{ }^{14} \mathrm{C}\right]$ allantoin. The decline in the specific radioactivity of allantoin in plasma following the injection of tracer was best described by a double exponential function, indicating that allantoin moves in and out of two or more kinetically distinct compartments. Sequestering of tracer in secondary or tertiary compartments in the body water appears likely to have resulted in overestimation of net flux of allantoin through the blood in the present study. In future studies, sampling of blood for several days after administration of tracer should alleviate this problem. About $80 \%$ of the $\left[{ }^{14} \mathrm{C}\right]$ allantoin injected was recovered as $\left[{ }^{14} \mathrm{C}\right]$ allantoin in urine during the $12 \mathrm{~h}$ after tracer injection, increasing to $94 \%$ after $4 \mathrm{~d}$. Allantoin-C also passed through the blood bicarbonate pool, suggesting that allantoin is degraded in the gastrointestinal tract. A small amount of allantoin-C (4\% of the net flux of allantoin through the blood pool) was apparently degraded to form bicarbonate- $\mathrm{C}$ in the rumen and postruminally, and subsequently appeared in blood bicarbonate-C. Transfer of allantoin-C into the rumen via saliva was insignificant. In view of these findings, the net flux of allantoin through the blood should be a better predictor of rumen microbial outflow than urinary allantoin excretion, because urinary excretion of purine derivatives must be adjusted for conversion of allantoin- $\mathrm{C}$ to blood bicarbonate when used to predict the flow of microbial protein from the rumen.
\end{abstract}

Allantoin: Purine: Microbial protein: HPLC: Sheep

Estimation of the rate of urinary excretion of purine derivatives (PD) is the basis of a non-invasive technique for the prediction of microbial yield from the rumen (Chen et al. 1990b). Circulating PD in sheep are metabolites of absorbed nucleotides and nucleosides derived mainly from microbial nucleic acids, and are excreted in urine in amounts that are proportional to the outflow of microbial cells from the rumen. Allantoin is the predominant PD in the urine of sheep, with uric acid, hypoxanthine and xanthine also being present in lower concentrations.

Numerous workers (Fujihara et al. 1987; Chen et al. 1990b, 1997; Balcells et al. 1991; Perez et al. 1996) have examined the relationship between inputs of either nucleic acids or RNA into the intestines of sheep and the excretion of PD in urine. Their research has shown that a close relationship exists but that excretion of derivatives of absorbed purines is not entirely via the urine. Incomplete urinary (renal) recoveries have also been reported following infusion of allantoin into the jugular vein of sheep (Chen et al. 1991; Surra et al. 1997) and for intravenously administered $\left[{ }^{15} \mathrm{~N}\right]$ uric acid in sheep (Chen et al. 1998). Chen et al. (1990a) suggested that saliva may be one significant non-renal route of excretion of $\mathrm{PD}$, but other researchers (Surra et al. 1993, 1997) have reported that the amounts transferred in saliva are negligible, thereby invoking the possibility of other non-renal routes of allantoin removal from the blood.

The relationship used for predicting outflow of microbial nucleic acid from the rumen may alter if non-renal excretion of PD is changed by unidentified factors (Chen et al. 1992). It occurred to us that the use of allantoin flux through the plasma pool as an indicator of exogenous purine absorption should overcome the problems posed by non-renal losses and provide an alternative and better indicator of microbial yield from the rumen. To date, there are no reports of estimates of allantoin flux rates through the blood of sheep. The aim of the study reported here was to estimate the flux rate of allantoin through the plasma pool and to investigate the kinetics of allantoin metabolism and excretion.

\footnotetext{
Abbreviations: PD, purine derivative; SR, specific radioactivity.

* Corresponding author: Dr L. P. Kahn, fax +612 67733275, email lkahn2@metz.une.edu.au
} 


\section{Materials and methods}

\section{Animals and conditions}

Two rumen-cannulated Merino $\times$ Border Leicester wethers, 2 years old, weighing 39.2 and $43.1 \mathrm{~kg}$ live weight, were kept in metabolism crates with continuous lighting and unrestricted access to water. For $12 \mathrm{~d}$ before (as well as during) the experiment the sheep were fed hourly (automatic overhead feeder) equal portions of a ration of oaten chaff (Avena sativa L.; 89.3 \% DM, $1.2 \% \mathrm{~N} ; 650 \mathrm{~g} /$ d) mixed with lucerne chaff (Medicago sativa L.; $87.2 \%$ $\mathrm{DM}, 2.8 \% \mathrm{~N} ; 250 \mathrm{~g} / \mathrm{d})$. Indwelling jugular catheters were placed in each sheep $24 \mathrm{~h}$ before the single injection of $\left[{ }^{14} \mathrm{C}\right]$ allantoin was administered.

The study was approved by the Animal Ethics Committee of the University of New England.

\section{Experimental procedures}

A solution containing $28 \mu \mathrm{Ci}\left[4,5-{ }^{14} \mathrm{C}\right]$ allantoin (Amersham International plc, Amersham, Bucks. UK; $38 \mu \mathrm{Ci} /$ $\mathrm{mg}$ ) and $15 \mathrm{mg}$ allantoin carrier in $10 \mathrm{ml}$ medical-grade physiological saline $(9 \mathrm{~g} \mathrm{Nacl} / \mathrm{l})$ was injected into the jugular catheter of each sheep. The catheter was immediately flushed with saline to ensure quantitative injection of all radioactive allantoin.

To determine the rate of conversion of allantoin-C to bicarbonate-C, it was necessary to measure the flux rates of bicarbonate in blood and rumen fluid. Thus, $2 \mathrm{~d}$ after the allantoin injection, $\mathrm{H}^{14} \mathrm{CO}_{3}{ }^{-}\left(42 \mu \mathrm{Ci}\right.$ and $5 \mathrm{mg} \mathrm{Na} \mathrm{CO}_{3}$ carrier in $10 \mathrm{ml}$ medical-grade physiological saline, made slightly alkaline with $\mathrm{NaOH}$ ) was injected into the jugular catheter of each sheep. The catheter was immediately flushed with physiological saline to ensure quantitative transfer of all radioactive material. After $1 \mathrm{~d}, \mathrm{H}^{14} \mathrm{CO}_{3}{ }^{-}$ (44 $\mu \mathrm{Ci}$ and $6.5 \mathrm{mg} \mathrm{Na}_{2} \mathrm{CO}_{3}$ carrier in $50 \mathrm{ml}$ water, made slightly alkaline with $\mathrm{NaOH}$ ) was injected through a stainless-steel probe into the rumen of each sheep. The probe was immediately flushed with water to ensure quantitative transfer of all radioactive material to the rumen.

\section{Sample collection and storage}

Samples of blood and rumen fluid were taken immediately before the injection of each isotope to determine the background radioactivity in the samples (which did not exceed that in water blanks). Blood and rumen fluid were sampled 5, 15, 30, 60, 90, 120, 180, 240, 360, 540, 760 and $1090 \mathrm{~min}$ after the $\left[{ }^{14} \mathrm{C}\right]$ allantoin injection, and $15,30,45$, $60,90,120,180,240,300$ and 400 min after the $\mathrm{H}^{14} \mathrm{CO}_{3}{ }^{-}$ injections. Samples of saliva were taken before, and 120 , 240, 540 and $1440 \mathrm{~min}$ after, injection of radioactive allantoin, using a method similar to that used by Chen et al. $(1990 a)$, i.e. by swabbing the mouth of the experimental sheep with small pre-weighed sponges which were then squeezed to release the saliva.

Blood samples were withdrawn from the jugular catheter and evenly fractionated. One fraction $(6 \mathrm{ml})$ was used for the determination of the specific radioactivity (SR) of blood bicarbonate-C by the method of Leng \& Leonard (1965).
The remainder was placed into a heparinized tube, cooled on ice and the plasma separated. Rumen fluid was withdrawn through nylon gauze and a portion $(4 \mathrm{ml})$ used to determine the SR of rumen bicarbonate-C (Leng \& Leonard, 1965).

Urine was collected over periods of $12 \mathrm{~h}$ on the first day and then daily for the next $3.5 \mathrm{~d}$ after injection of $\left[{ }^{14} \mathrm{C}\right]$ allantoin. A sufficient quantity of an anti-microbial chemical, thymol, was added to the urine collectors so that the final concentration in urine was about $2.2 \mathrm{mM}$. Immediately before the end of each sampling period, the metabolism crates were washed with deionized water to promote transfer of all urinary residues into the collecting vessel. Urine was subsampled at the end of each collection period. Plasma, saliva and urine were stored at $-20^{\circ} \mathrm{C}$ pending analysis.

\section{Tracer purity}

The radiochemical purity of the $\left[4,5-{ }^{14} \mathrm{C}\right]$ allantoin was determined by Amersham International plc to be $96.0 \%$ by TLC and $96.3 \%$ by HPLC. To check the integrity of the labelled allantoin on delivery, crystalline $\left[4,5-{ }^{14} \mathrm{C}\right]$ allantoin was dissolved in $4 \mathrm{ml}$ medical-grade physiological saline, subsampled and further diluted with deionized water. The diluted material was then injected $(20 \mu \mathrm{l})$ into a preequilibrated HPLC system. Analysis of the resulting chromatograms showed the existence of a single peak that had the same elution time and absorbance spectrum as unlabelled allantoin. The effluent from these chromatograms was fractionated and the associated radioactivity determined using a scintillation spectrophotometer (LSC; Packard Instrument Company Inc., Downers Grove, IL, USA). The radiochemical purity by this method was assessed to be $96.6 \%$, which was in close agreement with the Amersham specification.

\section{Analytical procedures for specific radioactivity of allantoin}

Separation and quantification of allantoin in urine. Allantoin concentration was determined in a fifty-fold dilution (deionized water) of urine using HPLC with a modified version of the method of Balcells et al. (1992a). The main modification was the use of two $\mathrm{C}_{18}$ reversedphase Nova-Pak ${ }^{\circledR}$ (Waters, Millipore Corporation, Milford, MA, USA) columns $(3.9 \mathrm{~mm} \times 300 \mathrm{~mm})$ connected in series: the effluent was also monitored at a higher wavelength $(214 \mathrm{~nm})$ and the flow rate was reduced to $0.6 \mathrm{ml} / \mathrm{min}$. The precision of allantoin determinations was checked by repeated injections ( $n 3$ ) of four different urine samples and the technique was further assessed by calculating the recovery of allantoin added at four levels to two different urine samples.

Separation and quantification of allantoin in plasma. Allantoin concentration in plasma was determined using the same column assembly as that used for determinations in urine. Optimal separation of allantoin from other polar compounds present in plasma was achieved with filtered $(0.45 \mu \mathrm{m}$, HVLP; Millipore Corporation) solutions of $0.1 \%(\mathrm{v} / \mathrm{v})$ orthophosphoric acid (A) and $0.1 \%(\mathrm{v} / \mathrm{v})$ orthophosphoric acid with $40 \%(\mathrm{v} / \mathrm{v})$ 
acetonitrile (B). The flow ( $0.6 \mathrm{ml} / \mathrm{min})$ consisted of $100 \%$ solution A from 0 to $10 \mathrm{~min}$. The percentage of solution A was then reduced to 0 and that of solution B increased to 100 over the next $20 \mathrm{~min}$, using a linear gradient. Solution $\mathrm{B}$ was then held at $100 \%$ until $35 \mathrm{~min}$ to ensure cleaning of the column. Initial conditions were then re-established by increasing solution A from 0 to $100 \%$ over the period 35-38 min, using a linear gradient, after which $100 \%$ solution A was maintained until 53 min.

Plasma $(400 \mu \mathrm{l})$ was placed into a regenerated cellulose filter assembly (Ultrafree $\mathrm{mc}^{\mathrm{TM}} 10000 \mathrm{NMWL}$ exclusion; Millipore Corporation) and centrifuged at $4^{\circ} \mathrm{C}$ at $3000 \mathrm{~g}$ for $15 \mathrm{~min}$ followed by a further $60 \mathrm{~min}$ at $12000 \mathrm{~g}$. Allopurinol (1 mmol/l) was added to the filtrate to act as an internal standard and $20 \mu \mathrm{l}$ of the resulting solution was injected (automatic injector WISP $710 \mathrm{~b}$; Water Associates, Milford, MA, USA). The technique for plasma analysis was assessed by calculating the recovery of allantoin added at two levels to two different plasma samples.

Specific radioactivity of allantoin. To determine the radioactivity in urinary allantoin, $0.2 \mathrm{ml}$ urine was acidified with glacial acetic acid to remove $\mathrm{H}^{14} \mathrm{CO}_{3}{ }^{-}$. The acidified urine solution was then mixed with $0.8 \mathrm{ml}$ water and $10 \mathrm{ml}$ of a toluene-Triton-X solution $(9: 4, \mathrm{v} / \mathrm{v}$ and containing $0.4 \%$ (w/v) 1,4-bis-[2-(5-phenyloxazoly)]-benzene and $0.02 \%(\mathrm{w} / \mathrm{v})$ 2, 5-diphenyloxazole) and counted on a scintillation spectrophotometer (Packard Instrument Company Inc). The external standard method was used to correct for quenching. SR was then calculated by dividing the radioactivity $(\mathrm{dpm} / \mathrm{l})$ by the urinary allantoin concentration (mg C/l) determined by HPLC.

Radioactivity associated with plasma was determined from a subsample of plasma filtrate. A weighed amount of filtrate was acidified (glacial acetic acid) to remove $\mathrm{H}^{14} \mathrm{CO}_{3}{ }^{-}$and then dried in a vacuum desiccator. The dried material was then dissolved in $1 \mathrm{ml}$ water and mixed with the toluene-Triton-X solution, as for determination of radioactivity in urine. This procedure was also used for saliva samples. To ensure that the label was specifically associated with allantoin, several urine and plasma samples were fractionated by HPLC before the radioactivity was determined in each fraction.

\section{Calculation of allantoin kinetics}

The SR $v$. time data were fitted assuming either a single-, double- or tri-exponential model by means of an iterative procedure based on the simplex algorithm that minimized the residual sum of squares using the program Ezfit (Noggle, 1992). The data were unweighted and a measure of the residual variance and a plot of the residuals $v$. time of sampling were used as the criteria to determine which of the models provided the 'best' fit. Estimates of compartment size, volume of distribution, proportion of $\mathrm{C}$ in the bicarbonate pool derived from allantoin (transfer quotient) and net and total flux were calculated from the model parameters (Shipley \& Clark, 1972), assuming that steadystate conditions applied. The relevant equations are given below:

$$
\text { compartment size }(\mathrm{Q} ; \operatorname{mg} \mathrm{C})=\mathrm{P} / \sum_{i=1}^{n} \mathrm{~A}_{i},
$$

where $\mathrm{P}$ is radioactivity injected $(\mu \mathrm{Ci})$ and $\mathrm{A}_{i}$ is zero time intercept of the $i$ th exponential component.

Volume of distribution (litres) $=\mathrm{Q} / \mathrm{C}$ bar,

where $\mathrm{C}$ bar is the mean allantoin concentration $(\mathrm{mg} \mathrm{C} / \mathrm{l})$ over the experimental period.

$$
\text { Net flux rate }(\mathrm{mg} \mathrm{C} / \mathrm{d})=\mathrm{P} / \sum_{i=1}^{n}\left(\mathrm{~A}_{i} / \mathrm{k}_{i}\right) \text {, }
$$

where net flux rate is the estimated flux through the primary compartment based on the extent to which tracer leaves and does not return during the experimental period, and $\mathrm{k}_{i}$ is rate constant of the $i$ th component.

$$
\text { Total flux rate }(\mathrm{mg} \mathrm{C} / \mathrm{d})=\mathrm{Q}\left(\sum_{i=1}^{n} \mathrm{~A}_{i}^{\prime} \mathrm{k}_{i}\right),
$$

where total flux rate is the entire flux through the primary compartment and $\mathrm{A}_{\mathrm{i}}^{\prime}$ are fractional zero time intercepts, e.g.

$$
\begin{gathered}
\mathrm{A}_{1}^{\prime}=\mathrm{A} 1 /\left(\sum_{i=1}^{n} \mathrm{~A}_{i}\right) . \\
\text { Transfer quotient }=\sum_{i=1}^{n}\left(\mathrm{~A}_{s i} / \mathrm{k}_{s i}\right) / \sum_{i=1}^{n}\left(\mathrm{~A}_{p i} / \mathrm{k}_{p i}\right),
\end{gathered}
$$

where transfer quotient is the proportion of $\mathrm{C}$ into pool $b$ irreversibly derived from pool $a, \mathrm{~A}_{s i}$ and $\mathrm{A}_{p i}$ are the zero time intercepts and $\mathrm{k}_{s i}$ and $\mathrm{k}_{p i}$ are the rate constants for the secondary and primary pool respectively.

\section{Results}

Determination of allantoin concentration by HPLC in four urine samples was found to be highly precise with the average CV being $2 \%$. Recovery of known amounts of allantoin added to urine and plasma samples was $95 \%$ (CV $3.0 \%)$ and $101 \%$ (CV $1.3 \%)$ respectively.

Throughout the experiment, both sheep ingested the entire ration of $900 \mathrm{~g} / \mathrm{d}$. Following intravenous injection of $\left[{ }^{14} \mathrm{C}\right]$ allantoin there was a rapid appearance of radioactive allantoin in urine. By $12 \mathrm{~h}$ both sheep had excreted in the urine about $80 \%$ of the $\left[{ }^{14} \mathrm{C}\right]$ allantoin injected. Urinary excretion of $\left[{ }^{14} \mathrm{C}\right]$ allantoin was monitored for the next $3.5 \mathrm{~d}$; at the end of this period cumulative recovery was about $94 \%$ of that injected (Fig. 1). Fractionation of compounds in urine and plasma samples by HPLC and determination of the radioactivity present in isolated allantoin verified that $100 \%$ of the radioactivity was present in allantoin.

Following intravenous injection of $\left[{ }^{14} \mathrm{C}\right]$ allantoin, the SR of allantoin in plasma declined in a manner that was best described by a double-exponential equation of the form:

$$
\mathrm{SR}_{\mathrm{t}}=\mathrm{A}_{1} \mathrm{e}^{-\mathrm{k}_{1} \mathrm{t}}+\mathrm{A}_{2} \mathrm{e}^{-\mathrm{k}_{2} \mathrm{t}},
$$




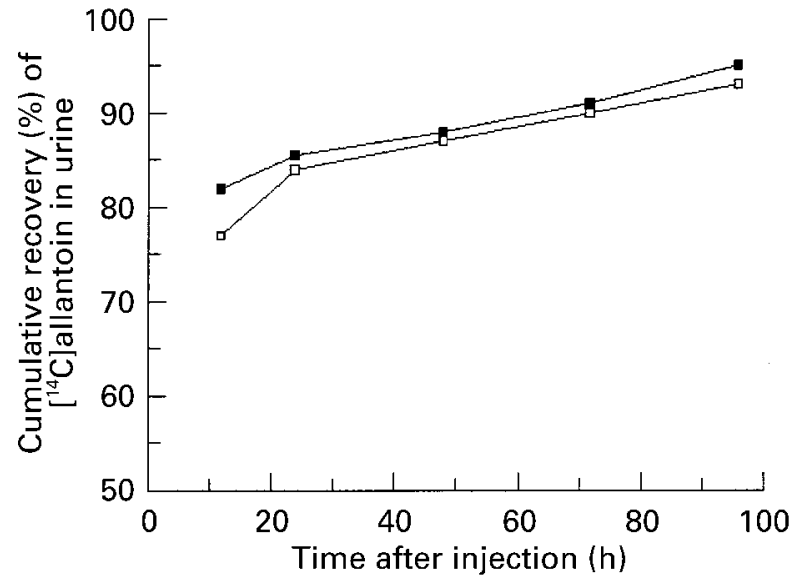

Fig. 1. Cumulative recovery of $\left[{ }^{14} \mathrm{C}\right]$ allantoin in urine of sheep $1(\square)$ and sheep $2(\boldsymbol{\square})$ following an intravenous injection of $\left[{ }^{14} \mathrm{C}\right]$ allantoin. Values were adjusted for dose purity of 0.966 . For details of animals and procedures, see p. 630 .

where $\mathrm{SR}_{t}$ is the $\mathrm{SR}$ of allantoin at time $t, \mathrm{~A}_{1}$ and $\mathrm{A}_{2}(\mu \mathrm{Ci} / \mathrm{g}$ C) are the intercept values and $\mathrm{k}_{1}$ and $\mathrm{k}_{2}(/ \mathrm{min})$ are the rate constants for the primary and terminal components of the curve. The terminal component of the SR $v$. time curve for both sheep became apparent after 2-3 $\mathrm{h}$. The parameter estimates defining the fitted curve for each sheep

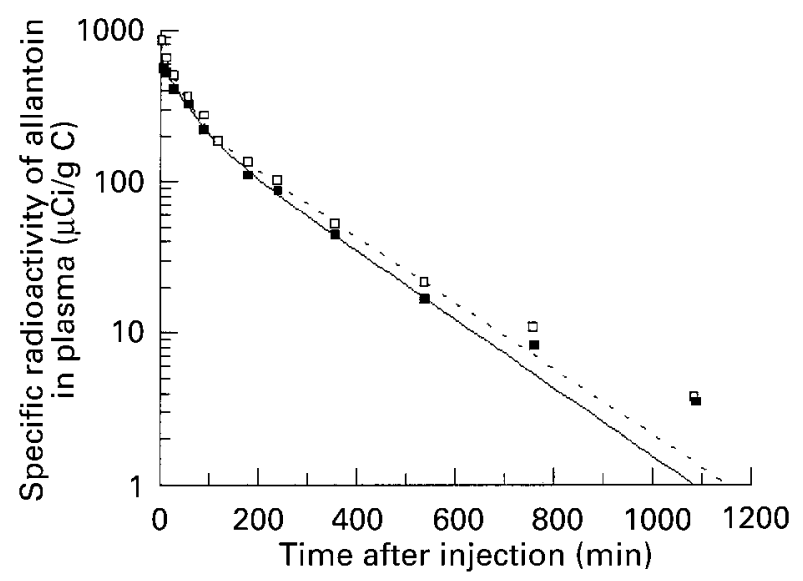

Fig. 2. Decline in specific radioactivity (SR) of plasma allantoin following intravenous injection of $28 \mu \mathrm{Ci}\left[{ }^{14} \mathrm{C}\right.$ ]allantoin. Equations 2 $(--)$ and $3(-)$ have been fitted to data for sheep $1(\square)$ and sheep 2 (घ) respectively.

$$
\begin{aligned}
& \mathrm{SR}_{\mathrm{t}}=503 \mathrm{e}^{-0.0237 \mathrm{t}}+317 \mathrm{e}^{-0.0050 \mathrm{t}}, \\
& \mathrm{SR}_{\mathrm{t}}=354 \mathrm{e}^{-0.210 \mathrm{t}}+278 \mathrm{e}^{-0.0052 \mathrm{t}},
\end{aligned}
$$

where $\mathrm{SR}_{\mathrm{t}}$ is $\mathrm{SR}$ of allantoin at time $\mathrm{t}$, based on the doubleexponential equation:

$$
\mathrm{SR}_{\mathrm{t}}=\mathrm{A}_{1} \mathrm{e}^{-\mathrm{k}_{1} \mathrm{t}}+\mathrm{A}_{2} \mathrm{e}^{-\mathrm{k}_{2} \mathrm{t}}
$$

where $A_{1}$ and $A_{2}(\mu \mathrm{Ci} / g C)$ are the intercept values and $k_{1}$ and $k_{2}$ (/min) are the rate constants for the primary and terminal components of the curve. The terminal component of the SR $v$. time curve for both sheep became apparent after 2-3 h. For details of animals and procedures see p. 630.
Table 1. Plasma allantoin concentration*, primary compartment size, volume of distribution, flux rates and transfer quotients, determined from the parameters for the fitted curves describing specific

\begin{tabular}{|c|c|c|}
\hline & Sheep 1 & Sheep 2 \\
\hline \multicolumn{3}{|l|}{ Allantoin in plasma (mg C/l)‡ } \\
\hline Mean & 5.4 & $5 \cdot 7$ \\
\hline SD & 0.23 & 0.35 \\
\hline Primary compartment size (mg C) & $33 \cdot 3$ & $42 \cdot 6$ \\
\hline Volume of distribution (litres) & $6 \cdot 1$ & 7.4 \\
\hline Total flux (mg C/d) & $790 \cdot 0$ & $860 \cdot 0$ \\
\hline Net flux (mg C/d) & $460 \cdot 0$ & $550 \cdot 0$ \\
\hline \multicolumn{3}{|l|}{ Transfer quotient $\times 10^{5}$} \\
\hline \multicolumn{3}{|c|}{ Percentage of $C$ derived from allantoin } \\
\hline In blood bicarbonate & 9.01 & $3 \cdot 26$ \\
\hline In rumen bicarbonate & $6 \cdot 18$ & 4.32 \\
\hline \multicolumn{3}{|l|}{ Bicarbonate total flux $(\mathrm{g} \mathrm{C} / \mathrm{d})$} \\
\hline Blood & $296 \cdot 0$ & $385 \cdot 0$ \\
\hline Rumen fluid & $46 \cdot 0$ & $137 \cdot 0$ \\
\hline
\end{tabular}
radioactivity in plasma allantoin $v$. time after a single injection of $\left[{ }^{14} \mathrm{C}\right]$ allantoin into the jugular vein of sheep $\dagger$

* Allantoin data are corrected for dose purity of 0.966 .

† For details of calculations, see p. 631.

$\ddagger$ Mean value and standard deviation are from fourteen blood samples taken over $24 \mathrm{~h}$.

(equations nos. 2, 3) provided a good fit to the data (Fig. 2).

$$
\begin{aligned}
& \text { Sheep } 1 \quad \mathrm{SR}_{\mathrm{t}}=503 \mathrm{e}^{-0.0237 \mathrm{t}}+317 \mathrm{e}^{-0 \cdot 0050 \mathrm{t}}, \\
& \text { Sheep } 2 \quad \mathrm{SR}_{\mathrm{t}}=354 \mathrm{e}^{-0 \cdot 0210 \mathrm{t}}+278 \mathrm{e}^{-0.0052 \mathrm{t}} .
\end{aligned}
$$

Compartment sizes, volumes of distribution of tracer, flux rates and transfer quotients, determined from the parameters for the fitted curves, and plasma allantoin concentrations are given in Table 1. Assuming a salivary flow rate of $10 \mathrm{l} / \mathrm{d}$ (Kay, 1966), it was calculated that less than $1 \%$ of the $\left[{ }^{14} \mathrm{C}\right]$ allantoin administered intravenously entered the rumen via saliva. Moreover, the appearance of $\mathrm{H}^{14} \mathrm{CO}_{3}{ }^{-}$in the blood and rumen after intravenous administration was a small proportion of the $\left[{ }^{14} \mathrm{C}\right]$ allantoin administered and the transfer quotient for bicarbonate-C in both blood and rumen fluid was not significant $(<0.01 \%)$. The quantitative transfer of allantoin- $\mathrm{C}$ to bicarbonate- $\mathrm{C}$ in rumen fluid and blood of each sheep was calculated by multiplying the respective transfer quotient by the total flux of $\mathrm{C}$ through the recipient rumen fluid or blood bicarbonate- $\mathrm{C}$ pool (determined by $\mathrm{H}^{14} \mathrm{CO}_{3}{ }^{-}$injection; Table 1 ). The rates of transfer of allantoin- $\mathrm{C}$ to bicarbonate in rumen fluid were 3 and $6 \mathrm{mg} \mathrm{C} / \mathrm{d}$ for sheep 1 and 2 respectively, and to bicarbonate-C in blood were 27 and $13 \mathrm{mg} \mathrm{C} / \mathrm{d}$ for sheep 1 and 2 respectively. The higher transfer to blood bicarbonate-C compared with rumen bicarbonate suggests that allantoin degradation in the gut predominantly occurs postruminally.

\section{Discussion}

Interest in purine metabolism in ruminants has increased with the understanding that purine absorption from the gut and urinary excretion of allantoin in sheep are closely related, and the relationship can be used to predict the flow of microbial matter from the rumen (Chen et al. 1990b; 
Balcells et al. 1991). Recovery of PD in urine is incomplete and has been estimated to be in the range 78-93\% (Chen et al. 1990b, 1997; Balcells et al. 1991; Perez et al. 1996), implying that 7-22\% of absorbed purines may be excreted via non-renal routes (i.e. transferred into the gut) or retained in the tissues. Urinary recovery of physiological quantities of allantoin administered directly into the blood by jugular infusion (Chen et al. 1991; Surra et al. 1997) is also incomplete in sheep, ranging from 62 to $105 \%$. Uncertainty about the constancy of partitioning excretion of PD between urinary and non-renal routes creates uncertainty about the accuracy of predictions. As tissue utilization of allantoin is unlikely, Chen et al. (1991) suggested that allantoin not excreted in urine may enter the gut via saliva, or by diffusion across the gut wall, with subsequent degradation by gut microflora.

Unlike hypoxanthine and xanthine, allantoin itself cannot be salvaged (i.e. reused in the biosynthesis of purines). Further, as there is apparently no allantoinase in ruminant tissues, allantoin is considered to be the final product of purine oxidation in ruminants (Stryer, 1988). In our study, the appearance in urine of about $80 \%$ of the $\left[{ }^{14} \mathrm{C}\right]$ allantoin in the $12 \mathrm{~h}$ following its intravenous injection confirmed that renal excretion is the major route of excretion of allantoin in sheep. However, over the next $3.5 \mathrm{~d}$ recovery of $\left[{ }^{14} \mathrm{C}\right]$ allantoin in urine continued and, at the end of that period, urinary excretion had accounted for about $94 \%$ of that injected. This high degree of recovery indicates that non-renal excretion of allantoin in sheep is lower than has previously been supposed. Nevertheless, some allantoin-C did appear in the blood bicarbonate pool. Passage of ${ }^{14} \mathrm{C}$ through the blood bicarbonate pool would occur if $\left[{ }^{14} \mathrm{C}\right]$ allantoin was secreted into the gastrointestinal tract and was degraded by resident bacteria (Belasco, 1954) releasing $\left[{ }^{14} \mathrm{C}\right]$ carbon dioxide to be reabsorbed and appear as labelled blood bicarbonate. Secretion of oxypurines such as hypoxanthine and xanthine into the intestinal lumen has been demonstrated in the hamster (Berlin \& Hawkins, 1968). Our results suggest that most of the degradation of allantoin in sheep occurs in sites other than the rumen, as less than $1 \%$ of the net flux of allantoin-C through blood plasma passed through the rumen bicarbonate pool and less than $1 \%$ of the $\left[{ }^{14} \mathrm{C}\right]$ allantoin given intravenously entered the gut via saliva.

Rapid passage of allantoin from blood to urine is to be expected, given the limited capacity for tubular reabsorption of allantoin in sheep (Chen et al. 1991). Allantoin in plasma is the primary mixing compartment and was found to be a relatively small pool (33-43 mg C; Table 1). Given the total flux of 790-860 mg C/d (Table 1), the blood allantoin pool would have been turning over approximately once every hour. In the absence of recycling, less than $0.1 \%$ of the dose of $\left[{ }^{14} \mathrm{C}\right]$ allantoin would have remained in the compartment after $12 \mathrm{~h}$. However, our results indicate that excretion of $\left[{ }^{14} \mathrm{C}\right]$ allantoin extended over a number of days following its intrajugular administration.

One explanation for its prolonged excretion is that allantoin in plasma exchanges reversibly with other pools (e.g. interstitial fluid). Labelled allantoin entering such compartments would have a low probability of release back into the primary compartment in the short term. The curves describing allantoin SR $v$. time provide evidence to support this notion. A second exponential component was apparent in the curves (Fig. 2), 2-3 h after $\left[{ }^{14} \mathrm{C}\right]$ allantoin injection. This situation could occur if allantoin was degraded and the $\mathrm{C}$ entered a derivative that was then recycled to allantoin. However, in the absence of mammalian allantoinase and non-significant transfer of allantoin- $\mathrm{C}$ to the rumen, such metabolic recycling is unlikely to occur in sheep. It is most likely that allantoin itself exists in kinetically distinct compartments within the body fluids. The last two data points in Fig. 2 suggest that there are probably more than two exponential components, even though they could not be mathematically fitted with confidence. These additional components could result from unaltered $\left[{ }^{14} \mathrm{C}\right]$ allantoin reentering the primary compartment (plasma allantoin) from other larger compartments (e.g. intracellular water), and the associated kinetics of allantoin exchange between such compartments could account for the prolonged urinary excretion of $\left[{ }^{14} \mathrm{C}\right]$ allantoin. The differences between values for total flux and net flux of allantoin (Table 1) support this interpretation. However, because only two of probably a larger number of compartments could readily be defined using our data, the true flux of allantoin through the plasma compartment (i.e. the net flux) was probably overestimated.

Plasma concentrations of allantoin averaged 113 and $120 \mu \mathrm{M}$ for sheep 1 and 2 respectively. These values are within the range reported for sheep by Chen et al. (1991), but are higher than those reported by Balcells et al. (1992b) and Chen et al. (1990b). Assuming that allantoin is distributed in non-plasma fluids at the same concentration as in plasma, its volume of distribution would have been 6.1 and 7.4 litres for sheep 1 and sheep 2 respectively. This level of distribution is equivalent to $16-17 \%$ of the live weight of the sheep, which is similar to that occupied by extracellular fluid which constitutes about $20 \%$ live weight (Eckert et al. 1989). It is probable that allantoin concentration in peripheral compartments is lower than that in plasma, which would alter the estimates of volume of distribution.

It has been suggested by Chen et al. (1990a) that any equations used to predict microbial yield, i.e. those based on the relationship between purine absorption and urinary excretion, may be inappropriate if the proportions of excretion via renal and non-renal routes (e.g. saliva) are not constant. These workers reported that the rate of excretion of PD in saliva was $10 \%$ of that in the urine. Their data show that the salivary concentration of allantoin and uric acid differed between the two experimental sheep by a factor of 2.3. Assuming that saliva flow did not change reciprocally, the proportion of purine loss via saliva would have had a large between-sheep variance. The results (Table 1) from the present study indicated that the transfer of allantoin-C to saliva and the rumen fluid was trivial $(<1 \%)$. These findings support those of Surra et al. (1993, 1997), and demonstrate that in sheep allantoin excretion via saliva is negligible, and therefore is unlikely to prejudice predictions of microbial yield from the rumen made using estimates of urinary allantoin excretion.

We conclude that plasma allantoin exchanges reversibly with other pools, and that this process delays the 
reappearance of tracer allantoin into the primary pool. As a consequence of the prolonged sequestration of labelled allantoin in the body, net flux of exogenous allantoin through plasma may be overestimated. To improve the accuracy with which net flux is estimated, blood or urine may need to be sampled for several days after a single injection of isotope. In those circumstances net flux of allantoin has the potential to be an accurate predictor of rumen microbial outflow.

Our results indicate that little allantoin is transferred to the rumen of sheep via saliva or by any other route, as the degradation of allantoin to bicarbonate- $\mathrm{C}$ in the rumen is quantitatively unimportant. Transfer of allantoin- $\mathrm{C}$ to blood bicarbonate accounts for $4 \%$ of the net flux of allantoin through the blood plasma, indicating that, however, small amounts of allantoin are degraded in the gut, mostly postruminally. Nevertheless, the fact that $96 \%$ of the allantoin that truly enters the primary compartment leaves in the form of allantoin provides support for the use of allantoin-excretion data to predict microbial yield from the rumen. A final cautionary note is that the results presented here do not preclude the possibility that other PD (i.e. xanthine, hypoxanthine or uric acid) may be more extensively degraded in the gut than allantoin and that, if this process occurs, confidence in predictions of microbial outflow from the rumen based on urinary PD excretion could be reduced.

\section{Acknowledgements}

The authors acknowledge Professor J. Rowe for valuable comments on the manuscript and the skilled technical assistance of Messrs F. Ball and S. Stachiw. Funding was made available by Australian woolgrowers through the International Wool Secretariat, who also provided a scholarship for L.K.

\section{References}

Balcells J, Guada JA, Castrillo C \& Gasa J (1991) Urinary excretion of allantoin and allantoin precursors by sheep after different rates of purine infusion into the duodenum. Journal of Agricultural Science, Cambridge 116, 309-317.

Balcells J, Guada JA, Peiro JM \& Parker DS (1992a) Simultaneous determination of allantoin and oxypurines in biological fluids by high-performance liquid chromatography. Journal of Chromatography 575, 153-157.

Balcells J, Parker DS \& Seal CJ (1992b) Purine metabolite concentrations in portal and peripheral blood of steers, sheep and rats. Comparative Biochemistry and Physiology 101B, 633-636.

Belasco IJ (1954) New nitrogen feed compounds for ruminantsa laboratory evaluation. Journal of Animal Science 13, 601610.

Berlin RD \& Hawkins RA (1968) Secretion of purines by the small intestine: transport mechanism. American Journal of Physiology 215, 942-950.

Chen XB, Calder AG, Prasitkusol P, Kyle DJ \& Jayasuriya MCN (1998) Determination of $15 \mathrm{~N}$ isotopic enrichment and concentrations of allantoin and uric acid in urine by gas chromatography/mass spectrometry. Journal of Mass Spectrometry 33, 130-137.

Chen XB, Chen YK, Franklin MF, Ørskov ER \& Shand WJ (1992) The effect of feed intake and body weight on purine derivative excretion and microbial protein supply in sheep. Journal of Animal Science 70, 1534-1542.

Chen XB, Fujihara T, Nakamura K, Mawuenyegah PO, Franklin MF \& Kyle DJ (1997) Response of urinary and plasma purine derivatives to various rates and infusion patterns of purines in sheep nourished by intragastric infusion. Journal of Agricultural Science, Cambridge 129, 343-352.

Chen XB, Hovell FD DeB \& Ørskov ER (1990a) Excretion of purine derivatives by ruminants: recycling of allantoin into the rumen via saliva and its fate in the gut. British Journal of Nutrition 63, 197-205.

Chen XB, Hovell FD DeB, Ørskov ER \& Brown DS (1990b) Excretion of purine derivatives by ruminants: effect of exogenous nucleic acid supply on purine derivative excretion by sheep. British Journal of Nutrition 63, 131-142.

Chen XB, Kyle DJ, Ørskov ER \& Hovell FD DeB (1991) Renal clearance of plasma allantoin in sheep. Experimental Physiology 76, 59-65.

Eckert R, Randall D \& Augustine G (1989) Animal Physiology Mechanisms and Adaptations, 3rd ed. New York: W.H. Freeman and Company.

Fujihara T, Ørskov ER, Reeds PJ \& Kyle DJ (1987) The effect of protein infusion on urinary excretion of purine derivatives in ruminants nourished by intragastric infusion. Journal of Agricultural Science, Cambridge 109, 7-12.

Leng RA \& Leonard GJ (1965) Measurement of the rates of production of acetic, propionic and butyric acids in the rumen of sheep. British Journal of Nutrition 19, 469-484.

Kay RNB (1966) The influence of saliva on digestion in ruminants. World Review of Nutrition and Dietetics 6, 292325.

Noggle JH (1992) Practical Curve Fitting and Data Analysis. Englewood Cliffs, NJ: Prentice Hall Inc.

Perez JF, Balcells J, Guada JA \& Castrillo C (1996) Determination of rumen microbial-nitrogen production in sheep: A comparison of urinary purine excretion with methods using $15 \mathrm{~N}$ and purine bases as markers of microbial-nitrogen entering the duodenum. British Journal of Nutrition 75, 699-709.

Shipley RA \& Clark RE (1972) Tracer Methods for In Vivo Kinetics. New York: Academic Press.

Stryer L (1988) Biochemistry, 3rd ed. New York: W.H. Freeman and Company.

Surra J, Guada JA, Balcells J \& Castrillo C (1993) Salivary losses of purine derivatives in sheep. Proceedings of the British Society of Animal Production Winter Meeting, pp. 175-176. Penicuik, Midlothian: British Society of Animal Production.

Surra J, Guada JA, Balcells J \& Castrillo C (1997) Renal and salivary clearance of purine derivatives in sheep. Animal Science 65, 83-91. 